\title{
Assessment of Physical Activity and Related Factors among Adults with Visual Impairments in Japan
}

\author{
Wakako Tatsuta ${ }^{1, *}$, Takayo Inayama ${ }^{2}\left(\mathbb{D}\right.$, Erika Yamanaka ${ }^{3}$ and Kazunori Ohkawara ${ }^{4}$ \\ 1 College of Sports Sciences, Nihon University, Tokyo 154-8513, Japan \\ 2 Department of Food and Health Sciences, Faculty of Health and Human Development, \\ The University of Nagano, Nagano 380-8525, Japan; inayama.takayo@u-nagano.ac.jp \\ 3 Graduate School of Human Health Sciences, Tokyo Metropolitan University, Tokyo 192-0397, Japan; \\ erichi4y@gmail.com \\ 4 Graduate School of Informatics and Engineering, University of Electro-Communications, \\ Tokyo 182-8585, Japan; ohkawara_kazunori@e-one.uec.ac.jp \\ * Correspondence: tatsuta.wakako@nihon-u.ac.jp; Tel.:+81-3-6453-1763
}

check for

updates

Citation: Tatsuta, W.; Inayama, T.;

Yamanaka, E.; Ohkawara, K.

Assessment of Physical Activity and Related Factors among Adults with Visual Impairments in Japan. Int. J. Environ. Res. Public Health 2022, 19, 2244. https://doi.org/10.3390/ ijerph19042244

Academic Editors: Sarah M. Camhi and Diego Augusto Santos Silva

Received: 9 November 2021

Accepted: 15 February 2022

Published: 16 February 2022

Publisher's Note: MDPI stays neutral with regard to jurisdictional claims in published maps and institutional affiliations.

Copyright: (C) 2022 by the authors. Licensee MDPI, Basel, Switzerland. This article is an open access article distributed under the terms and conditions of the Creative Commons Attribution (CC BY) license (https:// creativecommons.org/licenses/by/ $4.0 /)$.

\begin{abstract}
In Japan, there is a lack of physical activity data on health and disease among people with visual impairments, making it difficult to develop specific strategies for health promotion. This study aimed to identify moderate-to-vigorous physical activity (MVPA) among people with visual impairments in Japan, to examine the percentage of them who meet the MVPA recommended activity, and to identify factors related to MVPA. In this cross-sectional study, we analyzed a survey of 169 adults with visual impairments. The relationship between MVPA and related factors was analyzed using binomial logistic regression analysis. The median MVPA was 46 min/day for men and $36 \mathrm{~min} /$ day for women, respectively, aged $<65$ years, and $26 \mathrm{~min} /$ day for men and $34 \mathrm{~min} /$ day for women, respectively, aged $\geq 65$ years. Seventy-eight percent of the subjects achieved the recommendations by the $\mathrm{WHO}$, and $28 \%$ of the subjects $<65$ years had achieved the MVPA of $60 \mathrm{~min} /$ day recommended by the Japanese Active Guide. Self-efficacy (SE) for PA, recommended PA implementation behavior, subjective walking speed, and exercise habits were significantly associated with MVPA. The current status of MVPA time among people with visual impairments in Japan, as revealed by this study, indicates that it is important to set realistic goals and plan a step-by-step process to achieve the recommendation. In the future, it will be important to develop a program that encourages the improvement of SE and promotes PA.
\end{abstract}

Keywords: physical activity; health promotion; self-efficacy; blind; visual impairment; accelerometer

\section{Introduction}

Many studies have been reported on the determinants of health. In some countries, health disparities due to disability have been examined as one of the factors [1-3]. This is also true for the visually impaired, who are defined by the WHO as low vision or blind. Previous Australian studies have shown that adults with visual impairments have more than twice the risk of total mortality [1] compared with that of adults who are not visually impaired. It has also been reported that a group with chronic diseases had more visual impairments than the group without [2]. Furthermore, in an analysis of people aged $\geq 65$ years from the United States National Health and Nutrition Examination Survey (NHANES), those with visual impairments were more likely to be underweight and had higher biomarkers of lifestyle-related diseases, such as low-density lipoprotein cholesterol and homocysteine, than those without visual impairments [3]. There is an urgent need for efforts to reduce the risk of lifestyle-related disease for people with visual impairments, who are at higher risk of lifestyle-related diseases than those without visual impairments. To achieve this, moderate physical activity (PA) is essential, in addition to a healthy diet and better mental health. In 
fact, it has been reported that additional PA has a positive effect on body composition and physical fitness in people with visual impairments [4].

Decreased PA is associated with increased obesity, diabetes mellitus, some cancers, and other chronic diseases [5-7]. People with visual impairments often limit PA due to fear of falling and perceived risks to mobility [8,9]. In a number of previous international studies, people with visual impairment have also reported low PA. A meta-analysis revealed that children and young adults with visual impairments spent less time on moderate-tovigorous physical activity (MVPA) than those with normal sight, although the amount of low-intensity activity remained the same [10]. In a study of adult Portuguese men and women [11], the MVPA time was $25 \mathrm{~min} /$ day, and in a study of adult Brazilian men and women [12], the percentage of those achieving $30 \mathrm{~min} /$ day MVPA was $60 \%$. In a study using NHANES data from the USA, the average number of steps taken per day by people with visual impairments was 5992, about $40 \%$ fewer than those taken by people without visual impairments (9964 steps) [13]. Furthermore, MVPA time for people with visual impairments was reported to be $9.3 \mathrm{~min} /$ day, $60 \%$ shorter than that of people without visual impairments (23.5 $\mathrm{min} /$ day) [13]. On the other hand, there is a report that students with visual impairments do not differ from students without visual impairments in PA, such as the number of steps [14], so PA status may differ depending on group attributes.

As a measure to increase PA, PA recommendations and guidelines have been provided by various countries and international organizations. Specifically, the World Health Organization (WHO) recommends that adults should do at least 150-300 minutes of MPA; or at least 75-150 minutes of VPA; or an equivalent combination of MPA and VPA throughout the week, for substantial health benefits. The guideline recommends that for adults living with disability at least $300 \mathrm{~min} /$ week of MPA or $150 \mathrm{~min} /$ week of VPA is recommended for additional health benefits [15]. The Japanese PA guidelines, the Active Guide [16], recommends $60 \mathrm{~min} /$ day of MVPA for those aged 18-64 years, and $40 \mathrm{~min} /$ day or more of PA for those aged $\geq 65$ years defined as elderly in Japan, regardless of intensity. As already mentioned, there may be a discrepancy between the guidelines and the current situation in the people with visual impairments [8,9], where PA is more likely to be limited due to the characteristics of the disability. Therefore, it is necessary to understand their actual situation and then plan a practical, step-by-step intervention program to achieve their goals.

Although there are approximately 1.64 million people with visual impairments in Japan, very few studies have clarified the PA of people with visual impairments. Inoue et al. reported in a study using a questionnaire survey that Japanese adults with visual impairments have low PA levels, which may lead to a risk of motor dysfunction [17]. Japanese adults with visual impairments are expected to have lower PA, as in previous international studies. In order to examine stepwise achievement goals based on quantitative data, such as MVPA time and the number of steps taken, it is necessary to conduct research that employs not only questionnaire surveys but also methods that can quantitatively assess daily PA.

Planning an effective PA promotion program for people with visual impairments requires identifying factors associated with MVPA that may promote behavioral change, such as self-efficacy (SE) and environmental factors. In social cognitive theory [18], which describes a dynamic process in which preparatory factors, environmental factors, and behavior mutually influence each other, SE is considered one of the most important factors in promoting behavioral change. Although there are limited studies with people with visual impairments, Haegele et al. reported a positive correlation between self-efficacy and PA (MET-min/wk) in adults with visual impairments [19]. In addition to SE, studies of people without visual impairments have suggested that environmental factors, such as social contact and support by family and friends are related to PA [20,21]. For this population as well, it is necessary to examine whether MVPA is related to preparatory factors, such as SE, and surrounding support. 
The purpose of this study was to determine the MVPA time of Japanese adults with visual impairments, who are predicted to have low PA as in previous studies and to examine the percentage of those who meet the recommendation of MVPA (min). The recommendation of MPA and VPA was set at least 150-300 min of MPA or at least 75-150 min of VPA throughout the week in accordance with the WHO recommendation of, or an equivalent combination of MPA and VPA. In addition, The recommendation of MVPA was set at $60 \mathrm{~min} /$ day of MVPA for patients aged <65 years, in accordance with the Japanese PA guidelines. Since there is no recommended MVPA for those aged $\geq 65$ years, we set the MVPA to $30 \mathrm{~min} /$ day, referring to a previous study [22]. We also aimed to clarify the factors associated with MVPA.

\section{Materials and Methods}

\subsection{Study Design and Participants}

This cross-sectional study was undertaken in Japan between September and December 2019. In total, 184 adults (men: women ratio 120:64) with visual impairments participated in a survey. They all fit the WHO definition of low vision or blind. Participants were recruited in cooperation with the Japan Federation of the Visually Impaired (JFVI). This is because we wanted to recruit participants from all prefectures. The JFVI is the largest organization for people with visual impairments in Japan, with a membership of approximately 50,000 individuals with visual impairments.

The study procedure was as follows. First, the researchers obtained the consent and cooperation of the JFVI, after providing a written and verbal explanation of the study's significance and methodology. We requested JFVI to prepare people corresponding to the attributes of male and female, adulthood and old age, and JFVA suggested four people as the number of people that can be recruited by member organizations in all prefectures. The JFVI then mailed instructions and application forms to all 61 member organizations in Japan, requesting that each organization recruit four participants. Each member organization explained the study to its members either directly or via email, and permission to disclose contact information was obtained from members who expressed interest in participating. Upon receiving the list compiled by the JFVI, we informed individuals on the list via email or telephone of the survey outline, and accelerometers wrapped in cushioning material were mailed out to the participants. After that, the survey was explained to each participant by telephone. Consent was obtained by verbal confirmation of the participant's intention to consent and then, with permission, an audio recording of the participant's name and intention to consent. After obtaining consent, the researcher explained how to wear the triaxial accelerometer and the time frame for wearing it. The researchers explained that data obtained using the triaxial accelerometer would be excluded from the analysis if the wearing time was $<10 / \mathrm{h}$ day.

The study was conducted in accordance with the tenets of the Declaration of Helsinki and the Ethical Guidelines for Medical and Health Research Involving Human Subjects in Japan. The research protocol was approved by the Institutional Review Board at Nihon University College of Sports Sciences (2017-03).

\subsection{Attributes and Physical Characteristics}

Information concerning participants' sex, age, and vision levels was obtained from records that had been initially maintained by the JFVI. Information concerning the timing of the disability (congenital or mid-career), the form of residence and employment status, and subjective sense of health were confirmed during the telephone interviews. A participant's body mass index (BMI) was calculated from self-reported height and weight (weight $[\mathrm{kg}] /$ height $\left.\left[\mathrm{m}^{2}\right]\right)$ data. 


\subsection{Measurements}

\subsubsection{Physical Activity (PA)}

PA was monitored using a verified triaxial accelerometer (Active style PRO HJA-750C, Omron Healthcare Co., Ltd., Kyoto, Japan) [23], which has a sensitivity of $3 \mathrm{mG}$ and a range of $\pm 6 \mathrm{G}$. The epoch length was $10 \mathrm{~s}$, and an average of absolute values for $10 \mathrm{~s}$ was used for the combined acceleration. The wearing time and monitoring period was 7 days, including holidays, between September and November 2019. Holidays were defined as work-free days or weekends. Participants continued to wear it except when they could not (swimming, changing clothes, bathing, etc.) and while sleeping. After the 7-day measurement period, participants mailed the triaxial accelerometer to the researchers. The triaxial accelerometer data were imported into a computer once the device was returned. Data were analyzed only if available for $>3$ weekdays and $>1$ weekend day, during which time the device was worn for at least $600 \mathrm{~min} /$ day (and removed for $<120 \mathrm{~min} /$ day). In this study, we adopted the activity time according to the activity intensity of sedentary

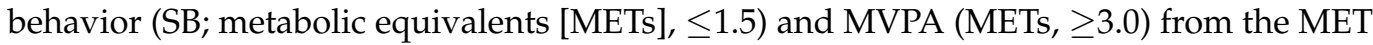
values evaluated every $10 \mathrm{~s}$.

\subsubsection{MVPA-Related Factors}

The factors associated with MVPA were asked about in a telephone interview. Participants responded to the following questions: (i) "Are you aware of the Active Guide in Japan?" (to determine awareness levels) and (ii) "Do you know how much PA is recommended for health promotion?" (to determine knowledge levels). Response options were "Yes" or "No"; (iii) "Are you confident in performing the recommendation of PA?" (to determine SE). Response options were (1) strongly agree, (2) agree, (3) disagree, or (4) strongly disagree; (iv) "Have you implemented the recommendations concerning physical activity levels?"(to determine behavior). Response options were: (1) every day, (2) often, (3) sometimes, (4) on a few occasions, or (5) not at all; (v) 'Are you in the habit of exercising regularly (defined as $\geq 30$ min once or twice a week or more, for $\geq 1$ year)?" Response options were: "Yes" or "No"; (vi) "What is the ambulatory speed compared to the same sex and age group?". Response options were (1) fast, (2) moderately fast, (3) moderate, (4) moderately slow, or (5) slow; To determine support around them, participants were asked: (vii) "Do you have a friend or someone to exercise with?" Responses were "Yes" or "No."

\subsection{Statistical Analysis}

Unanswered values were treated as missing values and excluded for each analysis. Data were analyzed at two age classifications: $<65$ years and $\geq 65$ years. The nominal and ordinal variables are expressed as numbers (\%). Continuous variables are presented as mean $( \pm \mathrm{SD})$ or median [1st quartile; 3rd quartile]. MVP, VPA and MVPA time is presented as median [1st quartile; 3rd quartile] because it was non-normally distributed by the Kolmogorov-Smirnov test. In addition, the number of people (\%) who achieved the recommendation of PA is shown. MPA and VPA were in accordance with WHO recommendations. MVPA was $\geq 60 \mathrm{~min} /$ day for those $<65$ years, in accordance with the Active Guide. Since the Active Guide recommends at least $40 \mathrm{~min} /$ day of PA regardless of intensity without MVPA recommendations for people $\geq 65$ years, we used a minimum of $30 \mathrm{~min}$ /day of MVPA as the standard, referring to previous research (Chen et al., 2015). Sex and age classification differences were compared using chi-square or Fisher's exact test for nominal and ordinal variables. Additionally, Continuous variables were compared using the Mann-Whitney U test.

The relationship between MVPA and factors related to MVPA was assessed through univariate and multivariate analyses, respectively, using binomial logistic regression analysis. The dependent variable, MVPA, was dichotomous above or below the median of each age classification. The independent variable was also dichotomous so that the responses from the four or more choices could be approached equally. The multivariate analysis 
provided two models (Models 1 and 2). Model 1 was adjusted for sex, age classification, area of residence, BMI (standard/other), current employment status, living arrangements, and area of residence. In Model 2, the time of disability and degree of disability were added to the adjustment variables in Model 1.

All statistical analyses were performed using IBM SPSS Statistics 21 (IBM Japan Inc., Tokyo, Japan), and the level of significance was set at 5\% for two-tailed tests.

\section{Results}

From 184 participants (men, $n=120$; women, $n=64$ ) who agreed to participate in this study, we excluded those who wore the device for $<10$ hours per day, those who had no data for $>4$ days including holidays, and those who had a disease that limited exercise $(n=15)$. In total, data were analyzed from 169 participants (men, $n=110$; women, $n=59$ ). Of the 169 participants, those with disabilities other than people with visual impairments were not included.

Table 1 shows the attributes and physical characteristics of the participants. Those who were blind accounted for $68 \%$ of all men and $71 \%$ of all women. Among the men, $3 \%$ had a BMI $<18.5,28 \%$ had a BMI $25-30$, and $6 \%$ had a BMI $\geq 30$. Among the women, $17 \%$ had a BMI $>18.5,14 \%$ had a BMI $25-<30$, and $3 \%$ had a BMI $\geq 30$.

Table 1. Study participants' attributes and physical characteristics.

\begin{tabular}{|c|c|c|c|c|c|c|c|c|c|}
\hline \multirow{3}{*}{$\begin{array}{c}\text { Variables } \\
\text { Blindness, }{ }^{1} n(\%)\end{array}$} & & \multicolumn{4}{|c|}{ Age, $<65$ Years } & \multicolumn{4}{|c|}{ Age, $\geq 65$ Years } \\
\hline & & \multicolumn{2}{|c|}{ Men, $n=74$} & \multicolumn{2}{|c|}{ Women, $n=40$} & \multicolumn{2}{|c|}{ Men, $n=36$} & \multicolumn{2}{|c|}{ Women, $n=19$} \\
\hline & & 46 & $(62)$ & 27 & $(68)$ & 29 & $(81)$ & 15 & (83) \\
\hline Congenital, ${ }^{2} n(\%)$ & & 40 & (54) & 19 & (48) & 13 & (36) & 6 & $(32)$ \\
\hline Worker, $n(\%)$ & & 67 & (91) & 27 & (68) & 27 & (75) & 8 & (42) \\
\hline Living alone, $n(\%)$ & & 18 & $(24)$ & 9 & (23) & 5 & (14) & 9 & (47) \\
\hline Height (cm), m (SD) & & 168.8 & $(6.6)$ & 154.9 & (6.6) & 165.4 & $(6.5)$ & 152.3 & $(4.9)$ \\
\hline Weight (kg), m (SD) & & 68.5 & $(12.6)$ & 54.4 & (8.0) & 64.5 & $(10.0)$ & 48.3 & $(6.9)$ \\
\hline Body mass index, $\mathrm{m}$ (SD) & & 24.0 & $(3.9)$ & 22.8 & (3.7) & 23.5 & $(3.1)$ & 20.8 & (2.7) \\
\hline BMI, $<18.5, n(\%)$ & & 2 & (3) & 5 & (13) & 1 & (3) & 5 & (26) \\
\hline BMI, 18.5-24, $n(\%)$ & & 45 & (61) & 26 & (65) & 24 & (67) & 13 & (68) \\
\hline BMI, $25-30, n(\%)$ & & 21 & (28) & 7 & (17) & 10 & $(28)$ & 1 & $(5)$ \\
\hline $\mathrm{BMI},>30, n(\%)$ & & 6 & $(8)$ & 2 & $(5)$ & 1 & (3) & 0 & (0) \\
\hline \multirow{3}{*}{ Self-rated health, $n(\%)$} & Very good & 26 & (35) & 11 & (28) & 12 & (33) & 10 & (53) \\
\hline & Good & 43 & (59) & 26 & (65) & 23 & (64) & 8 & (43) \\
\hline & Not so good & 4 & (6) & 1 & $(2)$ & 1 & $(3)$ & 1 & (5) \\
\hline
\end{tabular}

Missing answers were excluded. ${ }^{1}$ Blind participants were classified according to a self-report. Others were classified as having low vision. ${ }^{2}$. Congenital participants were classified according to a self-report. Abbreviations: BMI, body mass index; $n$, number; $\mathrm{m}$, mean; SD, standard deviation.

Table 2 shows the SB, PA, and percentage of people who achieved the PA recommendation, according to sex and age classification. In the group aged $<65$ years, the MVPA of men was 46 [28; 67] $\mathrm{min} /$ day, and that of women was 36 [26; 54] $\mathrm{min} /$ day. In $\geq 65$ years, the MVPA of men was 26 [14; 43] min/day, and that of women was 34 [14; 63] min/day. There was no significant difference by sex in either age group. Recalculation of MPA and VPA per day per week showed that $62(84 \%)$ men and $33(83 \%)$ women $<65$ years age group and $23(64 \%)$ men and $13(68 \%)$ women $\geq 65$ years and older age group achieved the WHO recommendations. Twenty-three men (31\%) and nine women $(22 \%)<65$ years of age met the MVPA of $60 \mathrm{~min} /$ day. Among those $\geq 65$ years, 16 men (44\%) and 12 women (63\%) met the MVPA of $30 \mathrm{~min} /$ day. 
Table 2. Sedentary behavior and physical activity according to sex and age subgroup classifications.

\begin{tabular}{|c|c|c|c|c|c|c|c|c|c|c|c|c|}
\hline \multirow{3}{*}{ PA } & \multicolumn{5}{|c|}{ Age, $<65$ Years } & \multicolumn{5}{|c|}{ Age, $\geq 65$ Years } & \multirow{2}{*}{ Men } & \multirow{2}{*}{ Women } \\
\hline & \multicolumn{2}{|c|}{ Men, $n=74$} & \multicolumn{2}{|c|}{ Women, $n=40$} & \multirow[b]{2}{*}{$p^{2}$} & \multicolumn{2}{|c|}{ Men, $n=36$} & \multicolumn{2}{|c|}{ Women, $n=19$} & \multirow[b]{2}{*}{$p^{2}$} & & \\
\hline & Median & $\begin{array}{l}\text { [1st Quartile; } \\
\text { 3rd Quartile] }\end{array}$ & Median & $\begin{array}{l}\text { [1st Quartile; } \\
\text { 3rd Quartile] }\end{array}$ & & Median & $\begin{array}{l}\text { [1st Quartile; } \\
\text { 3rd Quartile] }\end{array}$ & Median & $\begin{array}{l}\text { [1st Quartile; } \\
\text { 3rd Quartile] }\end{array}$ & & $p^{3}$ & $p^{3}$ \\
\hline Wear time (min/day) & 848 & {$[788 ; 941]$} & 886 & {$[826 ; 997]$} & 0.106 & 849 & {$[762 ; 986]$} & 927 & {$[785 ; 978]$} & 0.490 & 0.746 & 0.924 \\
\hline $\mathrm{SB}(\min /$ day $)$ & 402 & {$[319 ; 458]$} & 389 & {$[320 ; 448]$} & 0.693 & 395 & {$[328 ; 455]$} & 343 & {$[295 ; 445]$} & 0.215 & 0.952 & 0.313 \\
\hline $\operatorname{MPA}(\min /$ day) & 45 & {$[26,66]$} & 36 & {$[26,54]$} & 0.386 & 26 & {$[14,43]$} & 34 & {$[15,57]$} & 0.322 & 0.002 & 0.527 \\
\hline VPA (min/day) & 0.2 & {$[0,0.8]$} & 0 & {$[0,0.3]$} & 0.045 & 0 & {$[0,0.2]$} & 0 & {$[0,0.2]$} & 0.567 & 0.004 & 0.913 \\
\hline MVPA(min/day) & 46 & {$[28 ; 67]$} & 36 & {$[26 ; 54]$} & 0.196 & 26 & {$[14 ; 43]$} & 34 & {$[14 ; 63]$} & 0.184 & $<0.001$ & 0.901 \\
\hline \multirow[t]{2}{*}{$\begin{array}{c}\text { Non-ambulatory } \\
\text { (min/day) }\end{array}$} & 9 & {$[5 ; 16]$} & 15 & {$[8 ; 22]$} & 0.009 & 9 & {$[2 ; 12]$} & 17 & {$[5 ; 21]$} & 0.034 & 0.163 & 0.269 \\
\hline & $n$ & $(\%)$ & $n$ & $(\%)$ & $p^{4}$ & $n$ & $(\%)$ & $n$ & $(\%)$ & $p^{4}$ & $p^{5}$ & $p^{5}$ \\
\hline $\begin{array}{l}\text { WHO Recom- } \\
\text { mendedAchievers }\end{array}$ & 62 & (84) & 33 & (83) & 0.528 & 23 & (64) & 13 & (68) & 0.489 & 0.020 & 0.187 \\
\hline $\begin{array}{l}\text { MVPA } 60 \mathrm{~min} / \text { day } \\
\text { Achievers }\end{array}$ & 23 & (31) & 9 & (22) & 0.387 & 3 & (8) & 5 & (26) & 0.109 & 0.008 & 0.749 \\
\hline $\begin{array}{c}\text { MVPA } 30 \mathrm{~min} / \text { day } \\
\text { Achievers }\end{array}$ & 55 & (69) & 25 & (63) & 0.204 & 16 & (44) & 12 & (63) & 0.259 & 0.003 & 1.000 \\
\hline
\end{tabular}

Values are number (\%) or median [1st quartile; 3rd quartile]. $p 2$ Compared between the sexes using a Mann-Whitney U test. $p 3$ Compared between age categories using a Mann-Whitney $\mathrm{U}$ test. $p 4$ Compared between the sexes using a Fisher's exact test. $p 5$ Compared between age categories using Fisher's exact test. Abbreviations: MVPA, moderate-to-vigorous physical activity; n, number; SB, sedentary behavior. 
Table 3 shows the response distribution of factors related to MVPA. The items with a high percentage of Yes responses among those $<65$ years were 'high SE for PA' and 'no exercise habit', and the percentage of those with no exercise habit was significantly higher among women than among men. In the age group of $\geq 65$ years, the items with the highest percentages of Yes responses were 'high SE for PA and 'Performing the recommendation of $\mathrm{PA}^{\prime}$, and the percentages of those with high SE were significantly higher in women than in men.

Table 4 shows odds ratios for factors related to MVPA. The factors significantly associated with MVPA were SE for PA, recommended PA implementation behavior, ambulatory speed, and exercise habits. However, there was no relationship between MVPA and awareness, knowledge, and the presence of a friend during MVPA. 
Table 3. Related factors for MVPA according to sex and age subgroup classifications.

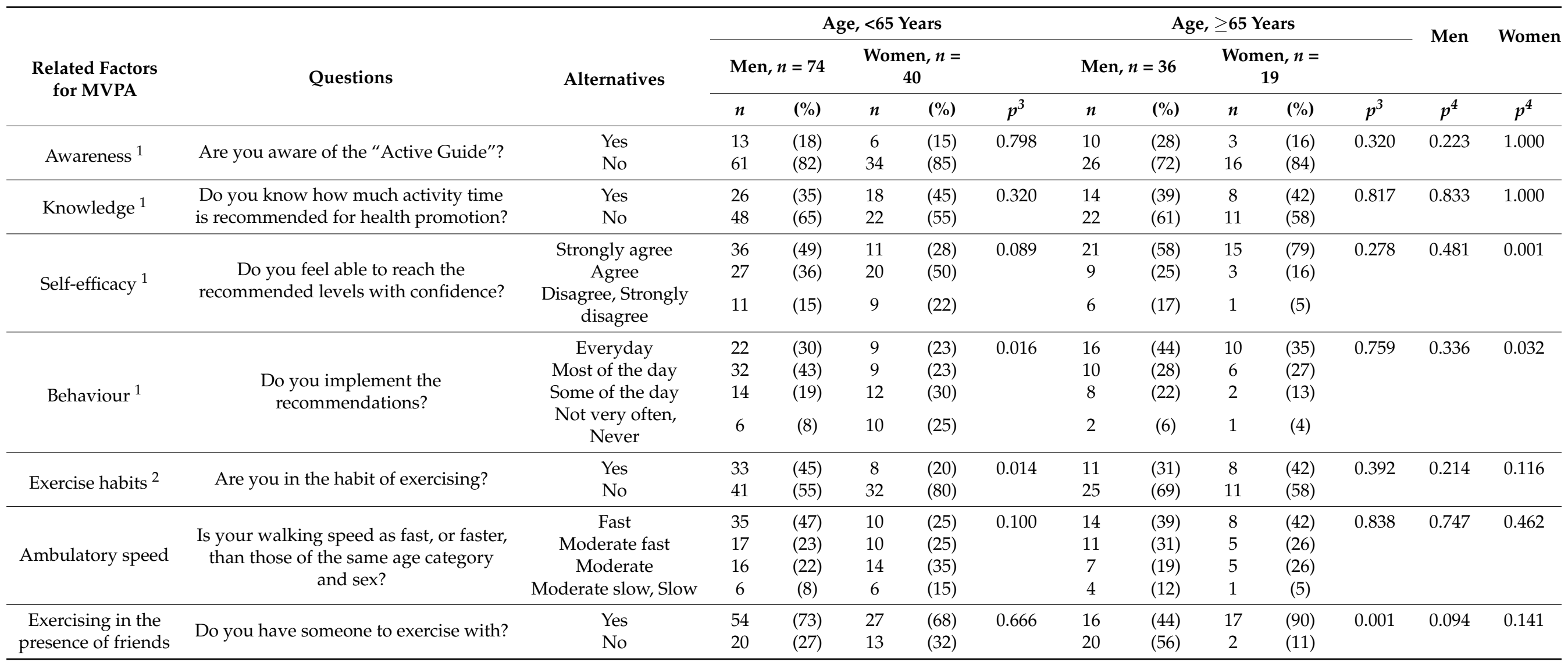

Values are presented as numbers (\%). ${ }^{1}$ The 'Activity Guide' refers to the official Japanese activity guidelines for health promotion. This guide recommends 60 min/day of activity of $\geq 3$ METs for people aged 18-64 years and $40 \mathrm{~min} /$ day of activity for people aged $\geq 65$ years, regardless of intensity, for health promotion. In this study, we asked questions according to each age category. ${ }^{2}$ Being in the habit of exercising refers to exercise performed for $\geq 30 \mathrm{~min}$ at least twice a week, and continuously for $>1$ year. $p^{3}$ Compared between the sexes using a chi-squared test. $p^{4}$ Compared between age groups according to sex using a chi-squared test. Abbreviations: METs, metabolic equivalents; MVPA, moderate-to-vigorous physical activity. 
Table 4. Odds ratios and confidence intervals for factors related to MVPA using logistic regression analysis $(n=169)$.

\begin{tabular}{|c|c|c|c|c|c|c|c|c|c|c|}
\hline \multirow{4}{*}{$\begin{array}{c}\begin{array}{c}\text { Factors } \\
\text { Relating to } \\
\text { MVPA }\end{array} \\
\begin{array}{c}\text { Awareness of } \\
\text { the activity } \\
\text { guide }\end{array}\end{array}$} & \multirow{4}{*}{$\begin{array}{l}\text { Questions } \\
\text { Are you aware of the } \\
\text { 'Active Guide'? }\end{array}$} & \multirow{3}{*}{\multicolumn{2}{|c|}{$\begin{array}{l}\text { Univariate } \\
\text { Analysis } \\
\text { OR (95\% CI) }\end{array}$}} & \multirow{4}{*}{$\begin{array}{c}p^{1} \\
0.635\end{array}$} & \multicolumn{6}{|c|}{ Multivariate Analysis } \\
\hline & & & & & \multirow{2}{*}{\multicolumn{2}{|c|}{$\begin{array}{c}\text { Model } 1 \\
\text { OR (95\% CI) }\end{array}$}} & \multirow{3}{*}{$\begin{array}{c}p^{1} \\
0.639\end{array}$} & \multirow{2}{*}{\multicolumn{2}{|c|}{$\begin{array}{c}\text { Model } 2 \\
\text { OR }(95 \% \text { CI })\end{array}$}} & \multirow{3}{*}{$\begin{array}{c}p^{1} \\
0.475\end{array}$} \\
\hline & & & & & & & & & & \\
\hline & & 0.83 & $(0.38-1.81)$ & & 0.83 & $(0.37-1.85)$ & & 0.74 & $(0.32-1.71)$ & \\
\hline Knowledge & $\begin{array}{l}\text { Do you know how } \\
\text { much activity is } \\
\text { recommended for } \\
\text { health promotion? }\end{array}$ & 1.61 & $(0.86-3.00)$ & 0.136 & 1.57 & $(0.83-2.97)$ & 0.164 & 1.52 & $(0.79-2.94)$ & 0.209 \\
\hline Self-efficacy & $\begin{array}{l}\text { Do you believe you } \\
\text { can achieve the } \\
\text { recommended level } \\
\text { of exercise, } \\
\text { with confidence? }\end{array}$ & 3.33 & $(1.76-6.28)$ & $<0.001$ & 3.66 & $(1.86-7.20)$ & $<0.001$ & 3.76 & $(1.87-7.57)$ & $<0.001$ \\
\hline Behavior & $\begin{array}{l}\text { Have you } \\
\text { implemented the } \\
\text { recommendations? }\end{array}$ & 3.60 & $(1.84-7.04)$ & $<0.001$ & 3.90 & $(1.92-7.91)$ & $<0.001$ & 4.05 & $(1.94-8.44)$ & $<0.001$ \\
\hline Exercise habits & $\begin{array}{c}\text { Are you in } \\
\text { the habit of } \\
\text { exercising regularly? }\end{array}$ & 2.69 & $(1.41-5.15)$ & 0.003 & 3.35 & $(1.67-6.70)$ & $<0.001$ & 3.95 & $(1.88-8.31)$ & $<0.001$ \\
\hline $\begin{array}{c}\text { Ambulatory } \\
\text { speed, very fast }\end{array}$ & $\begin{array}{c}\text { Are you walking } \\
\text { faster than those of } \\
\text { the same age category } \\
\text { and sex? }\end{array}$ & 2.84 & $(1.50-5.36)$ & $<0.001$ & 3.42 & $(1.74-6.73)$ & $<0.001$ & 3.62 & $(1.79-7.32)$ & $<0.001$ \\
\hline $\begin{array}{l}\text { Exercise in } \\
\text { the presence } \\
\text { of friends }\end{array}$ & $\begin{array}{l}\text { Do you have a friend } \\
\text { or someone to } \\
\text { exercise with? }\end{array}$ & 1.30 & $(0.68-2.50)$ & 0.427 & 1.34 & $(0.68-2.65)$ & 0.396 & 1.33 & $(0.67-2.67)$ & 0.214 \\
\hline
\end{tabular}

$p^{1}$ Correlations of MVPA with each factor were tested using logistic regression analysis adjusted for the following variables: Model 1: sex, age classification, BMI (standard/other), working, living arrangements, area of residence. Model 2: sex, age classification, BMI (standard/other), working, living arrangements, area of residence, time of disability, degree of disability. Abbreviations: BMI, body mass index; CI, confidence interval; MVPA, moderate-tovigorous physical activity; OR, odds ratio.

\section{Discussion}

This study was the first to assess the amount of PA in adults with visual impairments in Japan using a validated instrument [23], and to identify MVPA-related factors. In the participants with visual impairments in this study, many achieved the WHO recommendation, but MVPA time was shorter than the Japanese recommended time and it was not easy to achieve the recommendation of PA. However, even in this population, those with higher MVPA had higher SE for the recommended PA.

The MVPA time of the subjects in this study was not shorter than previous studies of people without visual impairment in other countries [11,12]. However, a previous study of people without visual impairment in Japan indicated mean averages between $76( \pm 27)$ minutes/day [24] and $72( \pm 49)$ minutes/day [25]. In people with non-visual impairments aged $\geq 65$ years, Chen et al. reported a median MVPA of $38 \mathrm{~min} /$ day [26], Yasunaga et al. reported a mean MVPA of $50( \pm 343) \mathrm{min} /$ day [27], and Amagasa et al. reported a mean MVPA of $54( \pm 40) \mathrm{min} /$ day [28]. In this study, the median is shown because of the non-normal distribution. When recalculation to mean, it is $50( \pm 30) \mathrm{min} /$ day for men and $43( \pm 25) \mathrm{min} /$ day for women < 65 years, and $31( \pm 20) \mathrm{min} /$ day for men and $42( \pm 29) \mathrm{min} /$ day for women $\geq 65$ years. As the data are not from the same survey, a simple comparison cannot be made. Nonetheless, it can be said that the amount of daily PA 
of adults with visual impairments is lower than that of adults without visual impairments, regardless of sex or life stage.

For those who achieved the WHO recommendation, $78 \%$ of all participants. In addition, $31 \%$ of men and $22 \%$ of women in the group aged $<65$ years achieved the Japanese Active Guide recommendation $60 \mathrm{~min}$ / day of MVPA, while $44 \%$ of men and $63 \%$ of women in $\geq 65$ years achieved $30 \mathrm{~min} /$ day of MVPA. Although there are very limited reports on adults without visual impairments in Japan, Kawakami et al. reported that $55 \%$ of adults achieved $23 \mathrm{METs} / \mathrm{hour} /$ week, which corresponds to $60 \mathrm{~min} /$ day of MVPA [29]. The recommended goal according to the Active Guide, MVPA $60 \mathrm{~min} /$ day or higher, was shown to require considerable effort for the adults with visual impairments. It has been reported that visual impairments reduce the sense of balance necessary to maintain a high level of PA, increase the fear of falling, and decrease ambulatory speed [12,30]. Nevertheless, it is still important to ensure MVPA, as the appropriate MVPA cut off value to distinguish between frail and non-frail individuals was $43.3 \mathrm{~min} /$ day in a Japanese frailty study of community residents aged $65-75$ years. The participants in this study had no diseases that would limit exercise, $76 \%$ were workers, few had a BMI $\geq 30$, and their subjective sense of health was good (Table 1). It is not easy to achieve the recommendation of MVPA even for healthy adults, such as the participants in this study, and it is necessary to gradually increase the dose of MVPA in order to promote health and prevent frailty in old age.

In order to bridge the gap between the actual amount of PA in terms of MVPA time and the recommendation, it is necessary to develop a program that incorporates behavioral science to promote PA. Model 2 included time of disability and degree of disability, but the items associated with MVPA did not change between models 1 and 2 . This result might be indicative that the years of impairment had no real effect on the factors measured. In our study, SE, behavior, exercise habits, and ambulatory speed-very fast were found to be the factors associated with PA, as shown in Table 4. In this paper, the focus was on SE, which is considered in social cognitive theory to be one of the most important factors in promoting behavioral change [18]. Many studies in people with and without visual impairments reported a positive association between PA and SE [19,31-33]. As in the previous study, SE for PA was positively related to MVPA in this study, while recognition of the Active Guide and knowledge of PA were not. This suggests the importance of focusing on improving SE, rather than providing guides and knowledge, when planning PA promotion programs for this population. Specifically, we can plan a program that uses the small-step technique to set behavioral goals one at a time and accumulate successful experiences, and that uses the modeling technique to share practical methods for promoting PA among participants and enhance SE. In the future, the challenge will be to verify, through intervention studies, the possibility that an improvement in SE will promote behaviors and exercise habits that have been positively associated with PA in this population, resulting in an increase in PA.

Our study had several limitations. First, the participants were not randomly selected but consisted of those who volunteered to participate, and our study may have been biased toward those who were physically active and interested in health promotion. Second, it did not ask about the level of disability according to the WHO definition. Third, many of the members of the organizations targeted in this study are blind, a higher percentage compared with that among people with visual impairments generally in Japan (38\% of Japanese people with visual impairments have a Level 1 disability certificate, which is equivalent to being blind); therefore, our findings cannot be generalized. Fourth, only a limited number of items were examined in item relation to MVPA. For example, in particular, in recent years, it has been pointed out that environmental factors, such as support from the surrounding environment and the presence of peers, promote behavioral change in relation to interpersonal factors. In this study, no association was found between MVPA and the presence of friends exercising together, but in the future, the association with other surrounding support and environmental factors, such as the presence of a sports center should be carefully examined. Finally, MVPA may have been underestimated because activity meters were removed during swimming and bathing. 
Despite these limitations, the present study clarified the actual status of MVPA among Japanese adults with visual impairments and the percentage of those achieving the recommendation of MVPA. An examination of factors associated with MVPA among people with visual impairments in Japan showed that it is important to focus on improving SE in order to bring about behavioral change. Jian et al. stated that most studies of environmental or behavioral interventions studied for reducing physical activity limitation and preventing falls in older people with visual impairments, the certainty of the evidence is generally low due to poor methodological quality and heterogeneous outcome measurements [34]. Social, psychological, and environmental factors that lead to behavior change based on objective measures of PA in daily living should also be examined.

\section{Conclusions}

The current status of MVPA time among people with visual impairments in Japan, as revealed by this study, indicates that it is important to set realistic goals and plan a step-by-step process to achieve the recommendation. In addition, since SE was identified as a factor associated with MVPA, it is necessary to develop a program with techniques to improve SE in order to promote PA.

Author Contributions: Conceptualization, W.T. and T.I.; methodology, K.O., E.Y. and T.I.; formal analysis, W.T.; investigation, W.T.; writing—original draft preparation, W.T.; writing-review and editing, T.I. and K.O.; funding acquisition, W.T. and T.I. All authors have read and agreed to the published version of the manuscript.

Funding: The present study was supported by JSPS KAKENHI (Grant numbers 20K02248).The funders had no role in the study design, data collection or analysis, decision to publish, or preparation of the manuscript.

Institutional Review Board Statement: The study was conducted in accordance with the tenets of the Declaration of Helsinki and the Ethical Guidelines for Medical and Health Research Involving Human Subjects in Japan. The research protocol was approved by the Institutional Review Board at Nihon University College of Sports Sciences (protocol code: 2017-03, date of approval: 13 December 2017).

Informed Consent Statement: Informed consent was obtained from all subjects involved in the study.

Data Availability Statement: The data presented in this study are available on request from the corresponding author.

Acknowledgments: The authors wish to thank the participants for their cooperation in this study. We also thank the staff of JFVI for their assistance.

Conflicts of Interest: The authors declare no conflict of interest.

\section{References}

1. McCarty, C.A.; Nanjan, M.B.; Taylor, H.R. Vision impairment predicts 5 year mortality. Brit. J. Ophthalmol. 2001, 85, 322-326. [CrossRef] [PubMed]

2. Zheng, D.D.; Christ, S.L.; Lam, B.L. Patterns of Chronic Conditions and Their Association with Visual Impairment and Health Care Use. JAMA Ophthalmol. 2020, 138, 387-394. [CrossRef] [PubMed]

3. Steinman, B.A.; Vasunilashorn, S. Biological risk of older adults with visual impairments. J. Nutr. Health Aging 2011, 15, $296-302$. [CrossRef] [PubMed]

4. Olszewska, A.; Jackowiak, A.; Chwałczyńska, A.; Sobiech, K.A. Physical activity as the main factor affecting body composition of the visually impaired. Physiother. Q. 2017, 25, 23-28. [CrossRef]

5. Inoue, M.; Yamamoto, S.; Kurahashi, N.; Iwasaki, M.; Sasazuki, S.; Tsugane, S. Japan Public Health Center-based Prospective Study Group. Daily total physical activity level and total cancer risk in men and women: Results from a large-scale population-based cohort study in Japan. Am. J. Epidemiol. 2008, 168, 391-403. [CrossRef]

6. Ohkawara, K.; Tanaka, S.; Miyachi, M.; Ishikawa-Takata, K.; Tabata, I.A. dose-response relation between aerobic exercise and visceral fat reduction: Systematic review of clinical trials. Int. J. Obes. 2007, 31, 1786-1797. [CrossRef]

7. Sawada, S.S.; Gando, Y.; Kawakami, R.; Blair, S.N.; Lee, I.; Tamura, Y.; Tsuda, H.; Saito, H.; Miyachi, M. Combined aerobic and resistance training, and incidence of diabetes: A retrospective cohort study in Japanese older women. J. Diabetes Investig. 2019, 10, 997-1003. [CrossRef] 
8. Nguyen, A.M.; Arora, K.S.; Swenor, B.K.; Friedman, D.S.; Ramulu, P.Y. Physical activity restriction in age-related eye disease: A cross-sectional study exploring fear of falling as a potential mediator. BMC Geriatr. 2015, 15, 64. [CrossRef]

9. Wang, M.Y.; Rousseau, J.; Boisjoly, H.; Schmaltz, H.; Kergoat, M.; Moghadaszadeh, S.; Djafari, F.; Freeman, E.E. Activity limitation due to a fear of falling in older adults with eye disease. Investig. Ophthalmol. Vis. Sci. 2012, 53, 7967-7972. [CrossRef]

10. Jung, J.; Leung, W.; Schram, B.M.; Yun, J. Meta-analysis of physical activity levels in youth with and without disabilities. Adapt. Phys. Activ. Q. 2018, 35, 381-402. [CrossRef]

11. Marmeleira, J.; Laranjo, L.; Marques, O.; Pereira, C. Physical activity patterns in adults who are blind as assessed by accelerometry. Adapt. Phys. Activ. Q. 2014, 31, 283-296. [CrossRef] [PubMed]

12. da Silva, R.B.P.; Marques, A.C.; Reichert, F.F. Objectively measured physical activity in Brazilians with visual impairment: Description and associated factors. Disabil. Rehabil. 2018, 40, 2131-2137. [CrossRef] [PubMed]

13. Smith, L.; Jackson, S.E.; Pardhan, S.; López-Sánchez, G.F.; Hu, L.; Cao, C.; Vancampfort, D.; Koyanagi, A.; Stubbs, B.; Firth, J.; et al. Visual impairment and objectively measured physical activity and sedentary behaviour in US adolescents and adults: A cross-sectional study. BMJ Open 2019, 9, e027267. [CrossRef] [PubMed]

14. Giese, M.; Herrmann, C. Assessment of Basic Motor Competencies in Children with Visual Impairments. Empir. Sonderpädag. 2020, 12, S167-S180.

15. World Health Organization. WHO Guidelines on Physical Activity and Sedentary Behaviour. Available online: File:///C: /Users/tatsuta.wakako/Downloads/9789240015128-eng\%20.pdf (accessed on 8 November 2021).

16. Ministry of Health, Labour and Welfare. Active Guide-Japanese Official Physical Activity Guidelines for Health Promotion. Available online: http:/ / www.nih.go.jp/eiken/info/pdf/active2013-e.pdf (accessed on 6 October 2021).

17. Inoue, S.; Kawashima, M.; Hiratsuka, Y.; Nakano, T.; Tamura, H.; Ono, K.; Murakami, A.; Tsubota, K.; Yamada, M. Assessment of physical inactivity and locomotor dysfunction in adults with visual impairment. Sci. Rep. 2018, 8, 12032. [CrossRef] [PubMed]

18. Bandura, A. Health Promotion by Social Cognitive Means. Health Educ. Behav. 2004, 31, 143-164. [CrossRef] [PubMed]

19. Haegele, J.A.; Kirk, T.N.; Zhu, X. Self-efficacy and physical activity among adults with visual impairments. Disabil. Health J. 2018, 11, 324-329. [CrossRef]

20. Nemoto, Y.; Sakurai, R.; Matsunaga, H.; Murayama, Y.; Hasebe, M.; Nishi, M.; Narita, M.; Fujiwara, Y. Social Contact with Family and Non-Family Members Differentially Affects Physical Activity: A Parallel Latent Growth Curve Modeling Approach. Int. J. Environ. Res. Public Health 2021, 18, 2313. [CrossRef]

21. Gallardo, L.O.; Abarca-Sos, A.; Doña, A.M. Expectancy-Value Model Related to Physical Activity Behaviors in Chilean and Spanish Adolescents. Int. J. Environ. Res. Public Health 2020, 17, 8219. [CrossRef]

22. Chen, T.; Narazaki, K.; Honda, T.; Chen, S.; Haeuchi, Y.; Nofuji, Y.Y.; Matsuo, E.; Kumagai, S. Tri-axial accelerometer-determined daily physical activity and sedentary behavior of suburban community-dwelling older Japanese adults. J. Sports Sci. Med. 2015, 14, 507-514.

23. Ohkawara, K.; Oshima, Y.; Hikihara, Y.; Ishikawa-Takata, K.; Tabata, I.; Tanaka, S. Real-time estimation of daily physical activity intensity by a triaxial accelerometer and a gravity-removal classification algorithm. Brit. J. Nutr. 2011, 105, 1681-1691. [CrossRef] [PubMed]

24. Yoshimura, E.; Ohkawara, K.; Ishikawa-Takata, K.; Yamada, S.; Tokui, M.; Funae, O.; Takimoto, H.; Katsukawa, F. Assessment of energy expenditure using doubly labeled water, physical activity by accelerometer and reported dietary intake in Japanese men with type 2 diabetes: A preliminary study. J. Diabetes Investig. 2019, 10, 318-321. [CrossRef] [PubMed]

25. Yano, S.; Koohsari, M.J.; Shibata, A.; Ishii, K.; Mavoa, S.; Oka, K. Assessing physical activity and sedentary behavior under free-living conditions: Comparison of active style Pro HJA-350IT and ActiGraph(TM)TM GT3X+. Int. J. Environ. Res. Public Health 2019, 16, 3065. [CrossRef] [PubMed]

26. Chen, S.; Chen, T.; Kishimoto, H.; Yatsugi, H.; Kumagai, S. Associations of objectively measured patterns of sedentary behavior and physical activity with frailty status screened by the frail scale in Japanese community-dwelling older adults. J. Sports Sci. Med. 2020, 19, 166-174. [PubMed]

27. Yasunaga, A.; Shibata, A.; Ishii, K.; Koohsari, M.J.; Inoue, S.; Sugiyama, T.; Owen, N.; Oka, K. Associations of sedentary behavior and physical activity with older adults' physical function: An isotemporal substitution approach. BMC Geriatr. 2017, 17, 280. [CrossRef]

28. Amagasa, S.; Inoue, S.; Marayama, H.; Fujikawa, T.; Kikuchi, H.; Fukushima, N.; Machida, M.; Chastin, S.; Owen, N.; Shobugawa, Y. Associations of Sedentary and Physically-Active Behaviors With Cognitive-Function Decline in Community-Dwelling Older Adults: Compositional Data Analysis From the NEIGE Study. J. Epidemiolt. 2019, 28, 503-508. [CrossRef]

29. Kawakami, R.; Murakami, H.; Miyatake, N.; Sawada, S.; Higuchi, M.; Miyachi, M. Physical activity reference for health promotion 2013 and the prevalence of metabolic syndrome: A cross-sectional study. Nihon Koshu Eisei Zasshi Jpn. J. Public Health 2014, 61, 705-717. (In Japanese) [CrossRef]

30. Klein, B.E.; Klein, R.; Lee, K.E.; Cruickshanks, K.J. Performance-based and self-assessed measures of visual function as related to history of falls, hip fractures, and measured gait time. The Beaver Dam Eye Study. Ophthalmology 1998, 105, 160-164. [CrossRef]

31. Wilroy, J.; Turner, L.; Birch, D.; Leaver-Dunn, D.; Hibberd, E.; Leeper, J. Development and evaluation of a social cognitive theory-based instrument to assess correlations for physical activity among people with spinal cord injury. Disabil. Health J. 2018, 11, 62-69. [CrossRef] 
32. Iwasaki, Y.; Honda, S.; Kaneko, S.; Kurishima, K.; Honda, A.; Kakinuma, A.; Jahng, D. Exercise Self-Efficacy as a Mediator between Goal-Setting and Physical Activity: Developing the Workplace as a Setting for Promoting Physical Activity. Saf. Health Work 2017, 8, 94-98. [CrossRef]

33. Dwyer, L.A.; Patel, M.; Nebeling, L.C.; Oh, A.Y. Independent Associations and Interactions of Perceived Neighborhood and Psychosocial Constructs on Adults' Physical Activity. J. Phys. Act. Health 2018, 15, 361-368. [CrossRef] [PubMed]

34. E, J.-Y.; Li, T.; McInally, L.; Thomson, K.; Shahani, U.; Gray, L.; Howe, T.E.; Skelton, D.A. Environmental and behavioural interventions for reducing physical activity limitation and preventing falls in older people with visual impairment. Cochrane Database Syst. Rev. 2020, 9, CD009233. [CrossRef] [PubMed] 